Correspondence

Alasdair Cook

alasdair.cook@uni-konstanz.de

\title{
Sulfoacetaldehyde is excreted quantitatively by Acinetobacter calcoaceticus SW1 during growth with taurine as sole source of nitrogen
}

\author{
Sonja Weinitschke, Katharina Styp von Rekowski, Karin Denger \\ and Alasdair M. Cook \\ Department of Biology, The University, D-78457 Konstanz, Germany
}

\begin{abstract}
Eighteen enrichment cultures with taurine (2-aminoethanesulfonate) as the sole source of combined nitrogen under aerobic conditions were all successful, and 24 pure cultures were obtained. Only three of the cultures yielded an inorganic product, sulfate, from the sulfonate moiety of taurine, and the others were presumed to yield organosulfonates. Sulfoacetate, known from Rhodopseudomonas palustris CGA009 under these conditions, was not detected in any culture, but sulfoacetaldehyde (as a hydrazone derivative) was tentatively detected in the outgrown medium of nine isolates. The compound was stable under these conditions and the identification was confirmed by MALDI-TOF-MS. Most sulfoacetaldehyde-releasing isolates were determined to be strains of Acinetobacter calcoaceticus, and a representative organism, strain SW1, was chosen for further work. A quantitative enzymic determination of sulfoacetaldehyde and its bisulfite addition complex was developed: it involved the NAD-coupled sulfoacetaldehyde dehydrogenase from $R$. palustris. A. calcoaceticus SW1 utilized taurine quantitatively and concomitantly with growth in, for example, an adipate-salts medium, and the release of sulfoacetaldehyde was stoichiometric. The deamination reaction involved a taurine dehydrogenase. Enrichment cultures to explore the possible release of organophosphonates from the analogous substrate, 2-aminoethanephosphonate, led to 33 isolates, all of which released inorganic phosphate quantitatively.
\end{abstract}

\section{INTRODUCTION}

Taurine (2-aminoethanesulfonate) (Fig. 1) is widely if disjunctively distributed in the biosphere (e.g. in mammals but not in plants), but degradation of the stable $\mathrm{C}$-sulfonate $\left(\mathrm{C}-\mathrm{SO}_{3}^{-}\right)$bond is limited to microbes (Huxtable, 1992). Correspondingly, many bacteria can utilize the compound in diverse metabolic situations (e.g. Cook \& Denger, 2002). Some researchers have used the compound as simultaneous sources of carbon (and energy), nitrogen and sulfur for aerobes (e.g. Chien et al., 1999), which did not expose the different phenomena involved in utilization of carbon and nitrogen via sulfoacetaldehyde and inducible sulfoacetaldehyde acetyltransferase (Xsc) on the one hand (Cook \& Denger, 2002; Denger et al., 2004a) and of sulfur via globally regulated taurine dioxygenase on the other (Eichhorn et al., 1997; Kertesz, 2000, 2001). The dissimilation of taurine in anaerobic respirations and fermentations emphasized the importance of Xsc in the degradative pathway(s) (Cook \& Denger, 2002), and the two reactions which generate the sulfoacetaldehyde have been examined. Taurine: pyruvate

The GenBank/EMBL/DDBJ accession numbers for the 16S rRNA gene sequences of $A$. calcoaceticus SW1 and Klebsiella oxytoca TauN1 are respectively AY823621 and AY823620. aminotransferase (EC 2.6.1.77) was initially thought to be the more common reaction (Cook \& Denger, 2002), but its catabolic role has been confirmed in only three organisms with sequenced genomes, Rhodococcus sp. strain RHA1 (Denger et al., 2004a), Silicibacter pomeroyi DSS-3 (Moran et al., 2004) and Rhodobacter sphaeroides 2.4.1 (K. Denger, unpublished; see also Novak et al., 2004). Taurine dehydrogenase was discovered first (Kondo et al., 1973), but only recently have its biochemical identity [taurine: ferricytochrome- $c$ oxidoreductase (deaminating) (EC 1.4.2.-); TauXY] and its widespread distribution been established (Brüggemann et al., 2004).

The widespread distribution of taurine dissimilation allowed a common transcriptional regulator, TauR, to be attributed to the degradative pathway, independent of the deamination used by the organism (Brüggemann et al., 2004; Denger et al., 2004a; Moran et al., 2004). In addition, a homeostatic mechanism to maintain the osmotic pressure in the cell following cleavage of the sulfonate moiety as sulfite was attributed to TauZ, a putative sulfate exporter (Rein et al., 2005).

Analysis of the sequence of the genome of Rhodopseudomonas palustris CGA009 revealed candidate genes to encode 
Taurine

Sulfoacetaldehyde
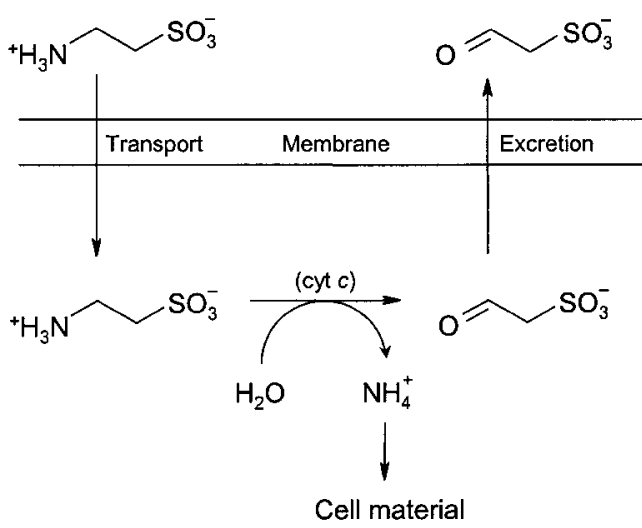

Fig. 1. Pathway that generates sulfoacetaldehyde from taurine in $A$. calcoaceticus SW1.

TauR and TauXY but not Xsc, and the organism was found to utilize taurine as a sole source of combined nitrogen under oxic and anoxic conditions (Denger et al., 2004b). $R$. palustris generated sulfoacetate quantitatively, and a sulfoacetaldehyde dehydrogenase was observed. It was concluded that taurine could be a major source of environmental sulfoacetate and that an exporter of sulfoacetate must be present in R. palustris (Denger et al., 2004b).

We thus proceeded to test whether taurine was commonly used by bacteria as a sole source of combined nitrogen concomitant with release of sulfoacetate. The results showed that release of an organosulfonate was common under these conditions, but that sulfoacetate was never observed and that sulfoacetaldehyde was often the product which was released.

\section{METHODS}

Materials. The bisulfite addition complex of 2-sulfoacetaldehyde dihydrate (53\% in sodium sulfate) was synthesized from 2-bromoacetaldehyde dimethylacetal and sodium metabisulfite and identified by NMR and IR (Denger et al., 2001): we were unable to convert this material to free sulfoacetaldehyde by published methods (White, 1988; Cunningham et al., 1998), as reported elsewhere (Gritzer et al., 2003). Phosphonoacetaldehyde, which had been synthesized by H. B. F. Dixon (Cambridge, UK), was kindly made available by J. P. Quinn (Belfast, Northern Ireland, UK). Other chemicals were from standard catalogues.

Organisms, growth media, growth conditions, cell disruption and enrichment cultures. $R$. palustris CGA009 was grown in 11 cultures in 51 Erlenmeyer flasks which were shaken at $30^{\circ} \mathrm{C}$ in the dark. The growth medium was a $50 \mathrm{mM}$ potassium phosphate buffer, $\mathrm{pH} 7 \cdot 2$, which contained $0.25 \mathrm{mM} \mathrm{MgSO}_{4}, 10 \mathrm{mM}$ DLmalate, $2 \mathrm{mM}$ taurine and trace elements (Thurnheer et al., 1986), as well as a seven-vitamin mixture (Pfennig, 1978), which was added after autoclaving. Cultures were inoculated (1\%) from a growing culture in the same medium and incubated until the turbidity indicated a protein concentration of $10 \mathrm{mg}$ protein $1^{-1}$ (7-8 days), when taurine was added to a final concentration of $2 \mathrm{mM}$. The culture was harvested $24 \mathrm{~h}$ later $\left(30000 \mathrm{~g}, 15 \mathrm{~min}, 4^{\circ} \mathrm{C}\right)$, washed in
$50 \mathrm{mM}$ potassium phosphate buffer, $\mathrm{pH} 7 \cdot 2$, containing $5 \mathrm{mM}$ $\mathrm{MgCl}_{2}$ and used immediately or stored frozen $\left(-20^{\circ} \mathrm{C}\right)$. Cells at about $250 \mathrm{mg}$ wet weight $(\mathrm{ml} \text { wash buffer })^{-1}$ were disrupted by eight passages through a chilled French pressure cell at $140 \mathrm{MPa}$. Debris was removed by centrifugation $\left(20000 \mathrm{~g}, 3 \mathrm{~min}, 4^{\circ} \mathrm{C}\right)$. The specific activity of the sulfoacetaldehyde dehydrogenase in the resulting crude extract was about 1.3 mkat ( $\mathrm{kg}$ protein $)^{-1}$.

The growth medium described above was used with minor modifications for enrichment cultures $(5 \mathrm{ml}$ in $50 \mathrm{ml}$ tubes) with $2 \mathrm{mM}$ taurine or $2 \mathrm{mM}$ 2-aminoethanephosphonate (ciliatine) as sole source of nitrogen. The carbon source in different sets of enrichments was (i) $5 \mathrm{mM}$ glucose plus $10 \mathrm{mM}$ glycerol plus $10 \mathrm{mM}$ DL-malate, (ii) $5 \mathrm{mM}$ glucose plus $10 \mathrm{mM}$ glycerol plus $10 \mathrm{mM}$ succinate, (iii) $10 \mathrm{mM}$ succinate, (iv) $5 \mathrm{mM}$ adipate, (v) $5 \mathrm{mM}$ benzoate, (vi) $20 \mathrm{mM}$ acetate or (vii) $10 \mathrm{mM}$ DL-lactate. Each set of enrichments was accompanied by controls containing either no added combined nitrogen or $2 \mathrm{mM}$ $\mathrm{NH}_{4} \mathrm{Cl}$ instead of taurine or 2-aminoethanephosphonate. The inocula were derived from the aeration tank of the wastewater treatment plant in Konstanz, from forest soil or from agricultural soil; in each case, the material was shaken with several batches of $50 \mathrm{mM}$ potassium phosphate buffer, $\mathrm{pH} 7 \cdot 2$, and decanted or centrifuged to remove any soluble nitrogenous material and inorganic solids. Inoculation left the cultures visibly turbid. Incubation for 1-3 days showed negligible growth in the negative controls and similar growth in both experiments and positive controls. After three passages in fresh medium, all cultures were plated on complex medium (Luria-Bertani medium; Gerhardt et al., 1994) and common colony morphologies were picked to fresh selective medium. A culture was considered pure when three cycles of homogeneous plates and growth in selective medium were attained. Organisms isolated to utilize 2-aminoethanephosphonate were transferred to medium suitable to detect the possible release of phosphate from the source of nitrogen. The two alterations were to buffer with $50 \mathrm{mM}$ MOPS/ $\mathrm{NaOH}, \mathrm{pH} 7 \cdot 2$ (instead of phosphate), and to add $0.5 \mathrm{mM}$ potassium phosphate as a source of phosphorus. Outgrown cultures were analysed for the presence and concentrations of 2-aminoethanephosphonate and inorganic phosphate.

Growth of Acinetobacter calcoaceticus SW1 was followed in $50 \mathrm{ml}$ cultures in $300 \mathrm{ml}$ Erlenmeyer flasks shaken in a water bath at $30^{\circ} \mathrm{C}$. The growth medium was as described for $R$. palustris (above), except that the carbon source was $5 \mathrm{mM}$ adipate and no vitamins were needed. Samples $(2 \mathrm{ml})$ were taken at intervals to measure turbidity and to determine the concentrations of protein, taurine and other organosulfonates and the ammonium and sulfate ions. When larger amounts of cells were required for enzyme assays, 11 cultures in 51 Erlenmeyer flasks were used. Rupture of harvested cells of $A$. calcoaceticus was essentially as described above, but only three passages through the French pressure cell were required.

Rhodococcus opacus ISO-5 was grown with taurine as the sole source of carbon and energy for growth, as described elsewhere (Denger et al., 2004a). Crude extract was generated (Denger et al., 2004a) to serve as positive controls for some enzyme assays.

Enzyme assays. Taurine:pyruvate aminotransferase was assayed discontinuously in $1 \mathrm{ml}$ reaction mixtures maintained at $37^{\circ} \mathrm{C}$ in a water bath. The reaction mixture contained $50 \mu \mathrm{mol}$ Tris $/ \mathrm{HCl}$, pH 9.0, $5 \mu \mathrm{mol} \mathrm{MgCl}_{2}, 5 \mu \mathrm{mol}$ taurine, $10 \mu \mathrm{mol}$ pyruvate, $100 \mathrm{nmol}$ pyridoxal $5^{\prime}$-phosphate and $0.3 \mathrm{mg}$ protein, with which the reaction was started. Samples were taken at intervals and taurine and alanine were determined. Crude extract from Rhodococcus opacus ISO-5 was used as a positive control. The reaction mixture was adapted to assay any 2-oxoglutarate-dependent transamination (EC 2.6.1.55) by replacing pyruvate with 2-oxoglutarate. Alanine dehydrogenase was assayed by a standard method (Laue \& Cook, 2000). Taurine dehydrogenase was assayed with either dichlorophenol indophenol 
(DCPIP) or beef-heart cytochrome $c$ as the electron acceptor (Brüggemann et al., 2004). Sulfoacetaldehyde dehydrogenase was assayed photometrically as the reduction of $\mathrm{NAD}^{+}$at $365 \mathrm{~nm}$. The reaction mixture $(1 \mathrm{ml})$ at about $22^{\circ} \mathrm{C}$ contained $50 \mu \mathrm{mol} \mathrm{Tris} / \mathrm{HCl}$, pH 9.0, $5 \mu \mathrm{mol} \mathrm{MgCl}_{2}, 4 \mu \mathrm{mol} \mathrm{NAD}{ }^{+}, 400 \mathrm{nmol}$ sulfoacetaldehyde (as the bisulfite addition complex) and $0 \cdot 1-0.3 \mathrm{mg}$ protein, with which the reaction was started.

Analytical methods. Growth was followed as turbidity (an $\mathrm{OD}_{580}$ of 1.0 was taken as equivalent to $250 \mathrm{mg}$ protein $1^{-1}$ ) and quantified as protein in a Lowry-type reaction (Cook \& Hütter, 1981). Reversed-phase chromatography was used to quantify taurine, 2aminoethanephosphonate, alanine or glutamate after derivatization with 2,4-dinitrofluorobenzene (Laue et al., 1997) or free sulfoacetaldehyde (presumably in equilibrium with the added bisulfite addition complex) after derivatization with 2-(diphenylacetyl)indane-1,3dione-1-hydrazone (Cunningham et al., 1998). Sulfate was determined turbidimetrically as a suspension of $\mathrm{BaSO}_{4}$ (Sörbo, 1987). Ammonium ion was assayed colorimetrically by the Berthelot reaction (Gesellschaft Deutscher Chemiker, 1996). Sulfoacetate or inorganic phosphate was quantified by ion chromatography with suppression (Denger et al., 2004b). The identity of sulfoacetaldehyde was confirmed by matrix-assisted, laser-desorption ionization timeof-flight mass spectrometry (MALDI-TOF-MS) in the negative ion mode with a matrix of 4-hydroxy- $\alpha$-cyanocinnamic acid; these determinations were done under contract by K. Hollemeyer (Technical Biochemistry, Saarland University, Saarbrücken, Germany). Values of apparent $K_{\mathrm{m}}\left(K_{\mathrm{m}}{ }^{\text {app }}\right)$ were derived by hyperbolic curve-fitting as cited elsewhere (Ruff et al., 2003). SDS-PAGE and staining were done by standard methods (Laemmli, 1970). Standard methods were used to establish Gram reaction, catalase and cytochrome $c$ oxidase activity (Gerhardt et al., 1994). A $1.4 \mathrm{kbp}$ fragment of the 16S rRNA gene of several organisms under study was amplified by PCR, sequenced and analysed essentially as described elsewhere (Brüggemann et al., 2004); primers 16S-27f and 16S-1492r (Weisburg et al., 1991) were used.

Determination of sulfoacetaldehyde with sulfoacetaldehyde dehydrogenase from $\boldsymbol{R}$. palustris. This enzyme was determined to have $K_{\mathrm{m}}$ app values of $26 \mu \mathrm{M}$ for sulfoacetaldehyde and $92 \mu \mathrm{M}$ for $\mathrm{NAD}^{+}$, as well as $12 \mathrm{mM}$ for $\mathrm{NADP}^{+} . \mathrm{NAD}^{+}$was obviously the physiological electron acceptor, and the high affinity for sulfoacetaldehyde made the catalyst a candidate for a specific (see Results) and sensitive enzymic determination of sulfoacetaldehyde (Bergmeyer, 1983). The enzyme could be enriched to about $28 \mathrm{mkat}$ ( $\mathrm{kg}$ protein $)^{-1}$ by two separations at different $\mathrm{pH}$ values on an anionexchange column, but this preparation still contained about 10 proteins in similar amounts (SDS-PAGE). We found that the soluble fraction was adequate to measure sulfoacetaldehyde in cell-free culture medium of $A$. calcoaceticus, provided the medium did not contain malate, the carbon source for growth of $R$. palustris. It was also apparent that both the free sulfoacetaldehyde and the bisulfite addition complex were substrates for the enzyme. The reaction mixture (in $1.0 \mathrm{ml}$ ) contained $50 \mu \mathrm{mol}$ Tris $/ \mathrm{HCl}, \mathrm{pH} \mathrm{9.0,5 \mu \textrm {mol }}$ $\mathrm{MgCl}_{2}, 4 \mu \mathrm{mol} \mathrm{NAD}{ }^{+}$and $\leqslant 60 \mathrm{nmol}$ sulfoacetaldehyde, and the value of $A_{365}$ was confirmed to be stable. The enzyme preparation $(0.3 \mathrm{mg}$ protein in $10 \mu \mathrm{l})$ was then added and the increase in the value of $A_{365}$ was followed. The reaction was complete in about $5 \mathrm{~min}$. It was possible to do the reaction with about $1 \mathrm{mM}$ sulfoacetaldehyde in the test and a long reaction time. Under these conditions, $1 \mathrm{mM}$ sulfoacetate was detected by ion chromatography after the enzyme reaction had ceased. We thus had confirmation that the required reaction was being catalysed.

\section{RESULTS}

\section{Sets of enrichment cultures}

A total of 18 enrichment cultures was set up in four series to obtain micro-organisms which could utilize taurine as the sole source of combined nitrogen for growth. The cultures differed in inoculum and source of carbon added. Every enrichment culture was positive, and 24 prokaryotic isolates were obtained (Table 1) as judged by light microscopy. None was found to produce sulfoacetate (compare Denger et al., 2004b), and only three produced sulfate (compare Denger et al., 2004a), so 21 isolates apparently released organosulfonates from taurine, which was quantitatively utilized in all strains except SW3.

Sulfoacetaldehyde was readily assayable by derivatization, and nine isolates were tentatively shown to generate this compound (Table 1). Isolate SW2 seemed to generate the

Table 1. Isolates obtained to utilize taurine as sole source of combined nitrogen for aerobic growth

Inocula were obtained from agricultural soil (A), forest soil (F) or activated sludge (S). Mixtures (i) and (ii) are detailed in Methods. ND, Not done.

\begin{tabular}{|llcll|}
\hline Isolate & $\begin{array}{c}\text { Inoculum, } \\
\text { carbon source }\end{array}$ & $\begin{array}{c}\text { Number of similar } \\
\text { isolates (source) }\end{array}$ & $\begin{array}{c}\text { Identity, } \\
\text { 16S rRNA }\end{array}$ & \multicolumn{1}{c|}{$\begin{array}{c}\text { Fate of } \\
\text { sulfonate }\end{array}$} \\
\hline SW1 & S, malate & $6(\mathrm{~S})^{*}$ & A. calcoaceticus & Sulfoacetaldehyde \\
SW2 & S, glucose & None & ND & Sulfoacetaldehyde $\dagger$ \\
SW3 & S, mixture (ii) & None & ND & Sulfoacetaldehyde \\
SW4 & F, mixture (ii) & $2(\mathrm{~S}, \mathrm{~F})$ & ND & Sulfate \\
TauN1 & S, succinate & $7(\mathrm{~A}, \mathrm{~F}) \ddagger$ & K. oxytoca & Isethionate \\
TauN2 & A, succinate & $1(\mathrm{~F}) \S$ & P. putida & Isethionate \\
TauN3 & A, mixture (i) & $1(\mathrm{~F})$ & ND & Isethionate \\
\hline
\end{tabular}

${ }^{\star}$ Fat, non-motile, encapsulated, short rods, which were Gram-negative, oxidase-negative and catalase-positive. $\dagger$ Sulfoacetaldehyde was formed in presence of glucose as carbon source.

¥Non-motile, short rods, which were Gram-negative, oxidase-negative and catalase-positive.

$\S$ Long, thin, motile rods, which were Gram-negative, oxidase-positive and catalase-positive. 
compound only in the presence of glucose as carbon source, and this behaviour was deemed too complex for the present study. Strain SW3 was also not examined further, because the nitrogen source was not utilized quantitatively. One bacterium, strain SW1, which was representative of seven morphologically indistinguishable isolates, was chosen for further work. The 16S rRNA gene of strain SW1 (and two similar organisms) was sequenced. The gene shared $>98.9 \%$ identity of position with all three sequences of the corresponding gene in the type strain of A. calcoaceticus. Simple taxonomic and physiological tests supported this identification (Table 1), so we presume the group of organisms, which were similar to strain SW1, was composed solely of strains of A. calcoaceticus. A. calcoaceticus SW1 was deposited with the DSMZ (Braunschweig, Germany) as DSM 16962. Strain SW1 apparently generated about 2 mol sulfoacetaldehyde (mol taurine) ${ }^{-1}$ (this apparent paradox is resolved below).

The organosulfonate generated by the other 12 isolates was at first unknown (Table 1); it was later shown to be isethionate (2-hydroxyethanesulfonate) (K. Styp von Rekowski, unpublished data). Three groups of organisms seemed to generate the compound. The largest group (eight organisms) was represented by strain TauN1, whose 16S rRNA gene was sequenced. This showed $99 \cdot 8 \%$ identity of position with the corresponding gene in the type strain of Klebsiella oxytoca, and its taxonomic and physiological properties supported this conclusion (Table 1). K. oxytoca TauN1 was deposited with the DSMZ as DSM 16963. A similar train of argument identified two strains as Pseudomonas putida, represented by strain TauN2 (Table 1). Two organisms were not identified.

A series of enrichment cultures yielded 33 isolates, all bacteria, able to utilize 2-aminoethanephosphonate as the sole source of combined nitrogen for growth. Each isolate utilized 2-aminoethanephosphonate quantitatively, but, in all cases, the phosphonate moiety was recovered quantitatively after growth as phosphate. There was no need to postulate an organophosphonate as an excreted product of metabolism of 2-aminoethanephosphonate.

\section{Confirmation of the identity of sulfoacetaldehyde, its stability and reproducible quantification}

We presumed that sulfoacetaldehyde would be labile, especially with the electron-withdrawing sulfonate moiety on the carbon atom adjacent to the aldehyde group. However, boiling the putative sulfoacetaldehyde in spent growth medium of $A$. calcoaceticus did not generate detectable sulfoacetate or alter the concentration of sulfoacetaldehyde, and the addition of several microlitres of fuming nitric acid also failed to generate sulfoacetate. The putative sulfoacetaldehyde was stable in growth medium.

Analysis of portions of growth medium by MALDITOF-MS in the negative-ion mode showed that neither

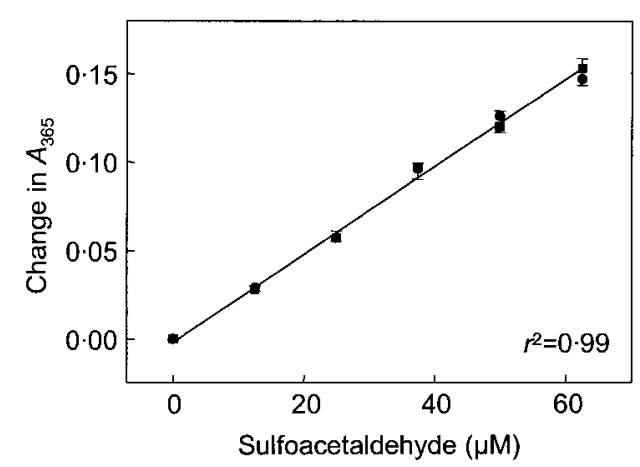

Fig. 2. Standard curve for the enzymic determination of sulfoacetaldehyde.

negative controls nor taurine $\left([M-1]^{-}=124\right)$ contained sulfoacetaldehyde, whereas spent taurine medium contained no detectable taurine but a product $\left([M-1]^{-}=123\right)$ which confirmed the presence of sulfoacetaldehyde $(M=$ 124). The identification, however, offered no quantification of the product.

We generated a third, enzymic, determination of the product using sulfoacetaldehyde dehydrogenase (EC 1.2.1.-) from $R$. palustris (Fig. 2). The quantification was thus provided by the molar absorption coefficient of NADH, which has been in use for over 60 years, and we confirmed that the purity of our salt-contaminated synthetic material is about $53 \%$ (see Denger et al., 2001). When tested at higher substrate concentrations, the enzymic formation of the expected concentration of sulfoacetate could be determined by ion chromatography. We found no compound which interfered with the reaction (acetaldehyde, phosphonoacetaldehyde, glyoxylate, glycolaldehyde, propionaldehyde and succinate semialdehyde were tested). Whereas the standard curve of the hydrazone derivative suggested that $2 \mathrm{~mol}$ sulfoacetaldehyde (mol taurine) ${ }^{-1}$ were formed (see above), the enzymic determination indicated unit stoichiometry (see below). We presume that our attempts to convert the bisulfite addition complex of sulfoacetaldehyde to the free aldehyde were inadequate (as observed elsewhere; Gritzer et al., 2003), because Cunningham et al. (1998) specify that the method only derivatizes the free aldehyde.

\section{Growth physiology of $A$. calcoaceticus SW1}

Strain SW1 grew with a specific rate $(\mu)$ of $0 \cdot 71 \mathrm{~h}^{-1}$ and a growth yield of $47 \mathrm{~g}$ protein (mol taurine-nitrogen $)^{-1}$ in adipate-salts medium (Fig. 3a); the same growth yield was obtained with the ammonium ion as sole source of nitrogen (not shown) and confirms the quantitative incorporation of nitrogen into cell material (e.g. Cook, 1987). Utilization of the nitrogen source was concomitant with growth, as was the release of sulfoacetaldehyde (Fig. 3b). Within experimental error, $1 \mathrm{~mol}$ sulfoacetaldehyde (mol taurine $)^{-1}$ was formed (Fig. 3b). The specific degradation 


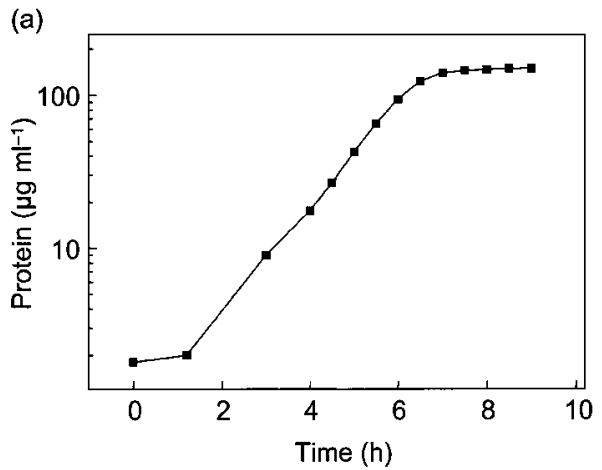

(b)

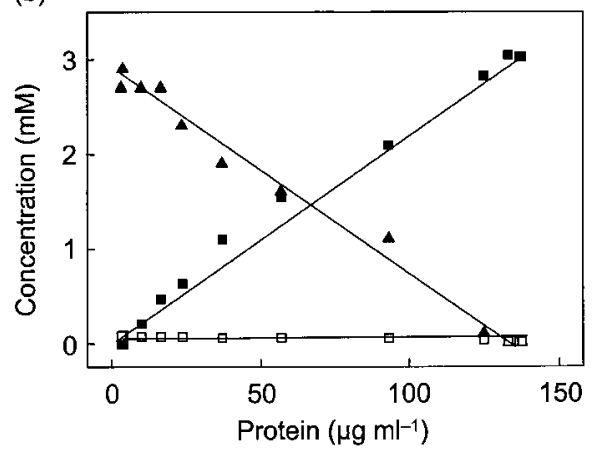

Fig. 3. Growth of $A$. calcoaceticus SW1 in $10 \mathrm{mM}$ adipatesalts medium with $2.5 \mathrm{mM}$ taurine as the sole source of combined nitrogen. In (a), the protein content is shown against time. In (b), the levels of taurine $(\boldsymbol{\Delta})$, sulfoacetaldehyde ( $\boldsymbol{\square})$ and the ammonium ion $(\square)$ are shown against protein content.

rate of taurine was calculated from the specific growth rate and the molar growth yield as $4 \cdot 2$ mkat $(\mathrm{kg} \text { protein })^{-1}$.

\section{Taurine dehydrogenase}

Two paths of deamination of taurine are known (see Introduction). No taurine: pyruvate aminotransferase, with the associated alanine dehydrogenase, was detected. The possibility was considered that $\beta$-alanine:2-oxoglutarate aminotransferase [nominally a taurine transaminase (EC 2.6.1.55)] was present, but no activity was detected. In contrast, inducible taurine dehydrogenase could be detected with DCPIP as the electron acceptor; the specific activity was about $0 \cdot 4$ mkat $(\mathrm{kg} \text { protein })^{-1}$. No activity was detected with beef-heart cytochrome $c$ as the electron acceptor, so we presume that a native cytochrome $c$ is needed.

\section{DISCUSSION}

The genome-enabled prediction, that $R$. palustris could utilize taurine and release a sulfonate, was confirmed when sulfoacetate was formed quantitatively (Denger et al., $2004 \mathrm{~b}$ ). The present paper, designed to test the generality of this phenomenon in new isolates, has confirmed that most organisms release an organosulfonate under these conditions, but that sulfoacetate was not the sulfonate released (Table 1). We wondered whether the apparently analogous 2-aminoethanephosphonate would be subject to similar transformations. The 33 isolates, all bacteria, which utilized this compound as a sole source of nitrogen all converted the phosphonate quantitatively to phosphate. Clearly, just as the biochemistry and regulation of cleavage of sulfoacetaldehyde (EC 2.2.3.15) and phosphonoacetaldehyde (EC 3.11.1.1) differ (Ternan \& Quinn, 1998; Ruff et al., 2003), so do the patterns of their degradation. Analogous experiments were done with cysteate, whose known initial reaction is deamination (Rein et al., 2005); only sulfate was recovered, never sulfopyruvate or sulfolactate (R. Gueta and A. M. Cook, unpublished data). The release of organosulfonates thus seems to be something characteristic of taurine metabolism.

The release of sulfoacetate by $R$. palustris was rationalized as both the NADH-yielding oxidation of the aldehyde to the acid and the irreversible conversion of the reactive aldehyde to the non-toxic acid (Denger et al., 2004b). The observation that sulfoacetaldehyde is neither labile nor especially reactive weakens the latter argument. The fact that many organisms need not carry out the oxidation at all, or even carry out a reduction to isethionate (K. Styp von Rekowski, unpublished data), also weakens the former argument. We suspect that the release of sulfoacetaldehyde into the environment is widespread, because bacteria able to dissimilate the compound have been observed (Lie et al., 1996).

The pathway by which strain SW1 obtains the ammonium ion is short, with only three steps, two of which are transporters (Fig. 1). The specific activity of the metabolic enzyme, also presumably membrane-bound (Brüggemann et al., 2004), was only $10 \%$ of that required for growth, but the natural electron acceptor was unavailable. Both ATP-binding-cassette transporters [TC 3.A.1.17.1] and tripartite, ATP-independent transporters [TC 2.A.56.4.1] are presumed to be involved with the uptake of taurine in different organisms (Brüggemann et al., 2004), but the nature of the sulfoacetaldehyde exporter is unknown, as is that for sulfoacetate in R. palustris (Denger et al., 2004b). The putative sulfate exporter in e.g. Paracoccus pantotrophus is apparently novel (Rein et al., 2005), so we hope to identify the genes involved in transport and oxidation of taurine and export of sulfoacetaldehyde, as well as the regulation, by characterizing taurine dehydrogenase, the corresponding gene(s) and its surroundings and developing testable, sequence-derived predictions.

\section{ACKNOWLEDGEMENTS}

We are grateful to Anja Dahler, Sonja Fraas and Anke Schwarzenberger for isolates and data generated in a practical course for advanced students. J. P. Quinn (Queen's University, Belfast) kindly shared his understanding of the metabolism of sulfonates and phosphonates with us, and supplied a sample of phosphonoacetaldehyde synthesized by H. B. F. Dixon (University of Cambridge, UK). The project was supported by the University of Konstanz and the LBS-Stiftung Wohnen und Umwelt. 


\section{REFERENCES}

Bergmeyer, H. U. (1983). Determination of metabolite concentrations with end-point methods. In Methods of Enzymic Analysis, pp. 163-181. Edited by H. U. Bergmeyer. Weinheim: Verlag Chemie.

Brüggemann, C., Denger, K., Cook, A. M. \& Ruff, J. (2004). Enzymes and genes of taurine and isethionate dissimilation in Paracoccus denitrificans. Microbiology 150, 805-816.

Chien, C.-C., Leadbetter, E. R. \& Godchaux, W., III (1999). Rhodococcus spp. utilize taurine (2-aminoethanesulfonate) as sole source of carbon, energy, nitrogen and sulfur for aerobic respiratory growth. FEMS Microbiol Lett 176, 333-337.

Cook, A. M. (1987). Biodegradation of $s$-triazine xenobiotics. FEMS Microbiol Rev 46, 93-116.

Cook, A. M. \& Denger, K. (2002). Dissimilation of the $C_{2}$ sulfonates. Arch Microbiol 179, 1-6.

Cook, A. M. \& Hütter, R. (1981). s-Triazines as nitrogen sources for bacteria. J Agric Food Chem 29, 1135-1143.

Cunningham, C., Tipton, K. F. \& Dixon, H. B. F. (1998). Conversion of taurine into $\mathrm{N}$-chlorotaurine (taurine chloramine) and sulphoacetaldehyde in response to oxidative stress. Biochem J 330, 939-945.

Denger, K., Ruff, J., Rein, U. \& Cook, A. M. (2001). Sulphoacetaldehyde sulpho-lyase (EC 4.4.1.12) from Desulfonispora thiosulfatigenes: purification, properties and primary sequence. Biochem J 357, 581-586.

Denger, K., Ruff, J., Schleheck, D. \& Cook, A. M. (2004a). Rhodococcus opacus expresses the xsc gene to utilize taurine as a carbon source or as a nitrogen source but not as a sulfur source. Microbiology 150, 1859-1867.

Denger, K., Weinitschke, S., Hollemeyer, K. \& Cook, A. M. (2004b). Sulfoacetate generated by Rhodopseudomonas palustris from taurine. Arch Microbiol 182, 254-258.

Eichhorn, E., van der Ploeg, J. R., Kertesz, M. A. \& Leisinger, T. (1997). Characterization of $\alpha$-ketoglutarate-dependent taurine dioxygenase from Escherichia coli. J Biol Chem 272, 23031-23036.

Gerhardt, P., Murray, R. G. E., Wood, W. A. \& Krieg, N. R. (1994). Methods for General and Molecular Bacteriology. Washington, DC: American Society for Microbiology.

Gesellschaft Deutscher Chemiker (1996). German Standard Methods for the Laboratory Examination of Water, Waste Water and Sludge. Weinheim: VCH.

Gritzer, R. F., Moffitt, K., Godchaux, W. \& Leadbetter, E. R. (2003). Sulfoacetaldehyde bisulfite adduct is a substrate for enzymes presumed to act on sulfoacetaldehyde. J Microbiol Methods 53, 423-425.

Huxtable, R. J. (1992). Physiological actions of taurine. Physiol Rev 72, 101-163.

Kertesz, M. A. (2000). Riding the sulfur cycle - metabolism of sulfonates and sulfate esters in gram-negative bacteria. FEMS Microbiol Rev 24, 135-175.
Kertesz, M. A. (2001). Bacterial transporters for sulfate and organosulfur compounds. Res Microbiol 152, 279-290.

Kondo, H., Kagotani, K., Oshima, M. \& Ishimoto, M. (1973). Purification and some properties of taurine dehydrogenase from a bacterium. J Biochem 73, 1269-1278.

Laemmli, U. K. (1970). Cleavage of structural proteins during the assembly of the head of bacteriophage T4. Nature 227, 680-685.

Laue, H. \& Cook, A. M. (2000). Purification, properties and primary structure of alanine dehydrogenase involved in taurine metabolism in the anaerobe Bilophila wadsworthia. Arch Microbiol 174, 162-167.

Laue, H., Denger, K. \& Cook, A. M. (1997). Taurine reduction in anaerobic respiration of Bilophila wadsworthia RZATAU. Appl Environ Microbiol 63, 2016-2021.

Lie, T. J., Pitta, T., Leadbetter, E. R., Godchaux, W., III \& Leadbetter, J. R. (1996). Sulfonates: novel electron acceptors in anaerobic respiration. Arch Microbiol 166, 204-210.

Moran, M. A., Buchan, A., González, J. M. \& 32 other authors (2004). Genome sequence of Silicibacter pomeroyi reveals adaptations to the marine environment. Nature 432, 910-913.

Novak, R. T., Gritzer, R. F., Leadbetter, E. R. \& Godchaux, W. (2004). Phototrophic utilization of taurine by the purple nonsulfur bacteria Rhodopseudomonas palustris and Rhodobacter sphaeroides. Microbiology 150, 1881-1891.

Pfennig, N. (1978). Rhodocyclus purpureus gen. nov. and sp. nov., a ring-shaped, vitamin $\mathrm{B}_{12}$-requiring member of the family Rhodospirillaceae. Int J Syst Bacteriol 28, 283-288.

Rein, U., Gueta, R., Denger, K., Ruff, J., Hollemeyer, K. \& Cook, A. M. (2005). Dissimilation of cysteate via 3-sulfolactate sulfo-lyase and a sulfate exporter in Paracoccus pantotrophus NKNCYSA. Microbiology 151, 737-747.

Ruff, J., Denger, K. \& Cook, A. M. (2003). Sulphoacetaldehyde acetyltransferase yields acetyl phosphate: purification from Alcaligenes defragrans and gene clusters in taurine degradation. Biochem J 369, 275-285.

Sörbo, B. (1987). Sulfate: turbidimetric and nephelometric methods. Methods Enzymol 143, 3-6.

Ternan, N. G. \& Quinn, J. P. (1998). Phosphate starvationindependent 2-aminoethylphosphonic acid biodegradation in a newly isolated strain of Pseudomonas putida, NG2. Syst Appl Microbiol 21, 346-352.

Thurnheer, T., Köhler, T., Cook, A. M. \& Leisinger, T. (1986). Orthanilic acid and analogues as carbon sources for bacteria: growth physiology and enzymic desulphonation. J Gen Microbiol 132, 1215-1220.

Weisburg, W. G., Barns, S. M., Pelletier, D. A. \& Lane, D. J. (1991). $16 \mathrm{~S}$ ribosomal DNA amplification for phylogenetic study. J Bacteriol 173, 697-703.

White, R. H. (1988). Characterization of the enzymic conversion of sulfoacetaldehyde and L-cysteine into coenzyme M (2-mercaptoethanesulfonic acid). Biochemistry 27, 7458-7462. 